\title{
A We6 Based Framework for Learning Styles Identification by Expert System
}

\section{Dr. Samy Abdelwahab Safaan}

Consultant Deanship of e-learning Qassim University, Assistant Professor Computer Sciences,

Nile Higher Institute for Business Technology in Computer

Sciences;

\section{Abstract}

7 he learning styles of the students has beenresearched and identified in many studies in the past. There are many models and frameworks proposed by the researchers. This study focused on the identifying the cognitive style of learning by the students via a web based expert system. Therefore, this study proposes an adaptive framework for the identification of the cognitive styles of the students. In this study, the expert system was developed with the help of the adaptation model and the student model. The web based infrastructure was designed and the system was tested on students of Buraidah Community College, Qassim University. Findings of the study show the adequacy of the versatile web-based learning system with powerfully distinguishing students' cognitive styles during perusing, along these lines approving the exploration motivations behind this examination. Another powerful result signifies positive and accurate outcomes in identification of the cognitive styles of learning of the students. The average staying time on the design web page was recorded and analyzed in order to check the accuracy of the students' cognitive style of learning.

Key Words: Expert System, Learning Styles, cognitive style, adaptation model, student model.

\section{Introduction}

The system of learning through the web resources applies different innovations related with sound and vision and, also it also emphasizes utilizing the hyperlinks to get different online assets. This will allow for the students to have greater authority and substantial materials compared to what their learning demands. They give students an 
undeniable degree of client control and rich materials (Margunayasa, et al., 2019). Nonetheless, learning through web resources has its restrictions. The students might overlook the significance to aptly get a hold of important data as the probabilities related with the web based courses are substantially increasing. Moreover, the individual variations of the students assume focal part in instruction including web-based learning (Nugroho,et al., 2020). The construction of learning through web resource and the strategies related with learning have been the two significant challenges related with learning through web resources, therefore, a significant undertaking is expected from the architects to address the procedure of building up the courseware that are web-based so that they can be implemented in the educational system according to the needs of the students (Mefoh,et al., 2017). Individuals have diverse cognitive styles that impact how they sort out and measure data, affecting their learning execution (Aggarwal,et al., 2019). The cognitive attributes of the students should be merged with the introduction of data to ensure the aptness and output of the system based upon the web resource incorporating the vital data related with the cognitive attributes of the students to adjust the ideal data in accordance with the students. Nonetheless, the numerous possibilities and ways of perceptions and processes of students' learning are neglected by the system of webbased learning (Valencia-Vallejo,et al., 2018).

A particular impediment may pose a trouble in distinguishing students' manners of cognition on the web. Various past examinations have gathered data about mental qualities, for example, manner of cognition by going through clients overall assessment surveys or the 
psychometric tests (Busari,et al., 2017). In any case, prominently asking clients probably won't spur them to respond to questions and it probably won't be appropriate in certain specific circumstances, especially for inconsistent clients (Enginnd and Vetschera, 2017). Thus, creating approaches to viably extricate mental data to distinguish the manner of cognition of students without upsetting learning measures of students is among the vital worries while merging the students' manner of cognition into versatile systems of web-based learning. One more obstruction while merging the students' manner of cognition into the system of learning through web is observed by the introduction of versatile resources of learning in web-based conditions. Planning versatile interfaces of web instinctively might truly not mirror data association of the students and handling inclinations. Be that as it may, there have been not many examinations to research the relationships between students' mental qualities and perusing practices (Aggarwal and Woolley, 2019). Hence, planning versatile interfaces of web that are appropriate with the students' mental qualities might prove to be another key challenge.

In accordance with the challenges, two-folded examination is preferred in this study. To begin with, this study will provide the system of learning through web resources by keeping the focus on the attributes related with students' cognition. This system focused upon the model of multi-layered forward feeding (MLFF) that hopes to understand the various attributes of students' cognition by observing students' conduct and without eliciting any patterns directly. (Bhatti, Dewani, Maqbool, and Memon, 2019) The ability of MLFF to deal with ambiguous and 
unambiguous information and its capability to generalize and gain from explicit models, capacity to be immediately refreshed with additional boundaries, and their pace in implementation that ensures their appropriateness for continuous exercising. At that point, students were introduced with a framework of multi-faceted interfaces according to their attributes on cognition. These multifaceted interfaces were designed in accordance with the relationship of students' cognition and the way by which they incorporate these cognitive abilities into the system of learning through web resources. Secondly, according to a research, the process of building MLFF for the students highlighted the appropriateness of the system as well. Two analytical questions were taken into account: the level of quality in finding out the attributes of students' cognition while commencing the system of learning through web resources by keeping MLLF in consideration and, the resulted commitment of the students while implementing upon the system of learning through web resources. (Dominic, Francis, and Pilomenraj, 2014.)

\subsection{Aim of the study}

The key aim of this study was to identify the impact of the web-based expert system on the learning style identification of the students.

\subsection{Objectives of the study}

The following objectives were developed in order achieve the aim of this research:

- To explore the web based expert system for the students

- To identify the student's cognitive style framework 
- To propose the web based system for the student's engagement in learning.

\section{Literature review}

\subsection{Web based Framework for Learning}

Utilizing the system of learning through web resources is assumed to advance a more significant extent of perception improvement since it demands affiliation along with the connection of various thoughts and data as opposed to just reviewing realities and information (Rukun and Irfan, 2020). In any case, making a system of learning in accordance with the students' prerequisites might be trying as the learning of students come along with various requirements as well as various learning qualities. The variety in students' learning qualities thus is a significant worry for creating a web web-page presence. An attractive system of learning through web resources becomes appealing while pursuing the objectives of learning, for example, attracting the students and building a system that attracts them so that they stay in it and inquire about it, emphasizing upon the procedure of students abiding by the system's connections to make sure the data gathering, and making the framework of information steady by providing the ideal picture of that system (Khamparia and Pandey, 2018). It is therefore, crucial to provide the students with elective approaches in order to enhance their learning processes. Nonetheless, various system related with learning are steady, hence, the students are provided with data that is latent. A basic viewpoint in building up a system related with learning is the way to execute customized administrations by comprehending the student's very own attributes. The most effective method to give the 
learning material regard to individual qualities (personalization) thus is one of the main points of contention for the system of learning through web resources. Recommendations have been given that a few students might encounter bewilderment and over-burden in cognition because of the colossal amount of data introduced and its sloppiness (Gupta and Raghuwanshi, 2019). To viably apply hypermedia to improve learning, Purnomo,et al., (2017) recommended two sorts of issues, composing related and learning-related, should be thought of. Marouf,et al., (2018) referenced that one basic issue of system configuration is the way to compose programming for few students while creating time in making it fill in like it was intended for every particular student utilizing in their time of learning.

A versatile system of learning through web resources gives customized data via consequently improving the association and introduction of the web page that is grounded in learning from students' perusing examples to accomplish customized services (Mudassir Khan, et al, 2016). On the off chance that the system is continually adapting or is constantly being adapted to students, the time of learning turns into an alternate sort of writing time (Wulandari,et al., 2019) so the web material can be adjusted by a specific student as per a client framework based on particular individual qualities and instructive technique for the system of learning through web resources (Valencia-Vallejo,et al., 2018). As indicated by Gupta and Raghuwanshi, (2019), a versatile system of web can be valuable in every territory of application in which the system is relied upon to be utilized by individuals with various objectives or attributes and in which the 
hyperspace is sensibly large. From the client's perspective, a versatile web-based system can assist a client with acquiring data in a structure that fits the client's attributes and satisfies the client's genuine necessities naturally. It can likewise assist a client with staying away from the issues of data over-burden, bewilderment, cognitive overburden, intermittent stream, content un-preparation, and absence of perception (Wulandari,et al., 2019). Then again, from the data supplier's perspective, the versatile webbased system is useful to convey data to clients all the more productively and successfully.

Most versatile web-based systems center around adjusting to client highlights, for example, objectives/errands, information, foundation, hyperspace experience, inclination, and interests (Aggarwal and Woolley, 2019). Notwithstanding these highlights, students' mental qualities are significant variables influencing their learning. Along these lines, remembering students' mental qualities for introducing interface of web is significant in learning process. The mental quality talked about in this investigation is the students' manner of cognition. Individuals coordinate and interaction data by a wide range of manners of cognition. The framework of manners of cognition suggest that an individual's conduct is probably going to be influenced by a cooperation between cognitive styles and the manner in which the data is organized, the method of introduction, and the kind of substance. They can show a person's inclinations for various kinds of data or various methods of exploring through or cooperating with the data space (Aggarwal and Woolley, 2019). Given a particular data structure or climate, the data will be understood more efficiently by a 
limited amount of people due to their unmistakable attributes of cognition. Assortment of models of the manner of cognition were formed by the analysis. The model of manner of cognition implemented while examining was the Myers Briggs Type gauge backed up by the hypothesis of manners of cognition proposed by Jung. It was chosen by the standards recommended by MyersBriggs:based on a two-dimensional model of data preparing, adequate legitimacy and unwavering quality information, and propriety for use with grown-ups. The instrument has broadly been implicated for grown-ups with adequate legitimacy and unwavering quality information (Nugroho,et al., 2020). It is based upon two principal cognitive capacities, insight (how individuals discover or retain data) and judgment (how individuals processor make judgment about the ingested data). Based upon discernment and assessment, the four cognitive manners of Interpersonal, Self-expressive, Comprehension and Mastery have been examined (Fig. 1). A style is a fundamental direction toward the world based upon useful inclinations (detecting versus instinct, thinking versus feeling) portrayed by specific interests, propensities for brain, and individual practices. An expanding measure of examination zeroing in on the effect of students' attributes has been directed in web-based learning (Gupta and Raghuwanshi, 2019). Normally, mental data is gathered by requesting that student's complete assessment polls before the learning measures. Nonetheless, prominently asking students may cause them to feel awkward and it probably won't be pertinent in certain specific circumstances. Instructions to adequately separate mental data to fabricate the framework of client without upsetting students' learning 
measures consequently assumed to be one of the critical worries for joining students' manner of cognition into versatile learning through the system of web resources and is also among the aims of this examination.

\section{Sensing}

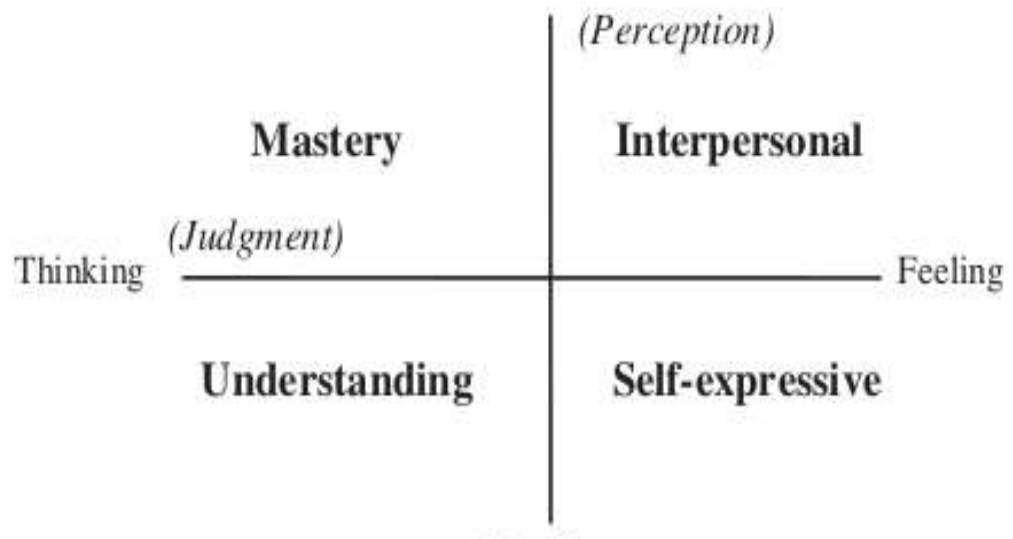

Intuitive

Figure 1: Myers-Briggs Model for Cognitive Styles

\subsection{Students' Psychological Characteristics Identification and Data Collection}

Transformation choices in versatile web-based systems are based on the client's qualities addressed in the client model. To give versatile interfaces in web-based learning systems, it is vital to recognize students' conduct and learning inclinations (Prickett, et al., 2020) . Gathering information about students to decide their qualities, accordingly is a significant factor for creating versatile learning systems. The strategies for acquiring information about clients incorporate unequivocal and understood methodologies (Nugroho,et al., 2020). Express methodologies request that clients input their own information by expecting them to respond to inquiries to 
portray their inclinations or other important boundaries (Koć-Januchta, et al., 2017). Be that as it may, clients are normally not spurred to respond to questions and they are regularly hesitant to give individual information (Margunayasa, et al., 2019.

Moreover, posing clients to answer inquiries may intrude on the perusing processes (Enginnd and Vetschera, 2017). Numerous clients are reluctant to be intruded on during perusing and to input any data to a web-based system (Gupta and Raghuwanshi, 2019). Accordingly, straightforwardly requesting client information to fabricate/update the client model may not be suitable in certain applications. Rather than requesting that clients input their own information, verifiable methodologies record the client's response to every approaching information thing to consequently gather the client model (Valencia-Vallejo,et al., 2018). As there is more worry for the client protection and clients are less ready to give private information, handling with implied client information is getting significant. To improve adaptivity, numerous systems attempt to distinguish clients to hold their drawn out information. For this reason, numerous systems insert mechanisms,such as treats and following programming specialists, in the client's program as well as record client IP address so the system can distinguish the client as he/she interfaces with the system later. Nonetheless, this may strife with protection worries of clients (Wulandari,et al., 2019). Hence, to ensure client privacy,building a momentary client model without utilizing client information got from different meetings is significant for versatile web-based systems (Wulandari,et al., 2019) and is one of the objectives of this examination. 
Normally, express methodologies are utilized to gather mental data by requesting that student's complete assessment polls before the learning measures (Enginnd and Vetschera, 2017). In any case, students probably won't be happy to finish an assessment and it probably won't be pertinent in certain unique situations. Recommendation have been made that perusing conduct gives the possibility to remove few mental related with the student, utilized to guide the interfaces of web towards the student (Margunayasa, et al., 2019). Consequently, perceiving students' cognitive styles by dissecting certainly gathered students' perusing practices is a potential modify local to distinguish students' manner of cognition. The errand of recognizing singular qualities including the manner of students' cognition is like the acknowledgment of character in which the two of them include the characterization of highlights from a conceivably limitless number of potential data sources (Enginnd and Vetschera, 2017). A few scientists have recommended that neural organizations could perform well in arrangement due to

(1) their example acknowledgment capacity on loose or not completely got information,

(2) their capacity to sum up and gain from explicit models,

(3) their capacity to be immediately refreshed with additional boundaries, and

(4) their pace of execution makes it suitable for perpetual implication (Koć-Januchta, et al., 2017).

Purnomo,et al., (2017) proposed a bunch of three diverse neural organization ways to deal with recognizing 
the manners of learning of the students for versatile plans to learn in conditions that are based upon the utilization of web and portable. An impartial-fluffy organization was used for choosing the apt manner of learning, an impartialfluffy organization to arrange the manner of learning with a hereditary calculation to prepare, and a self-coordinating component map (SOM) to recognize the manners of learning of the students. Aggarwal and Woolley (2019) built up a MLFF to distinguish the manner through which the students learn by noticing the practices they pursue, taking into account; the determination of connection types, utilization of implanted help gadgets not-visited/visited and ESDs hubs. The proposed model was proved to be well in distinguishing the Kinesthetic, Auditory and Visual learning manners of the students. Notwithstanding recognizing the manners of students' learning, the MLFF model has likewise been effectively embraced to evaluate students' meta cognitive information level by noticing their internet perusing practices (Saini, et al., 2014). In that review, like Nugroho,et al., (2020), perusing conduct incorporated the utilization of ESDs and route between visited/unvisited web pages. That review likewise confirmed the appropriateness of the proposed model and demonstrated no critical contrasts of appraisal exactness concerning the web page structures.

Accomplishments of past investigations in the system of learning through web resources have become the reason for the particular examination to embrace the MLFF in order to distinguish the cognitive attributes of the students without requesting that they go through the assessment surveys completely. At the point of identification of cognitive attributes of the students, a versatile system of 
learning through web resources ought to have the option to appropriately introduce the students with multi-faceted interfaces.

\section{System Architecture}

The suggested versatile system of learning through web resources involved two sub models, the student model and the transformation model. The students' perusing practices were collected by the system for refreshing the student model to recognize the cognitive attributes of the students and suggested learning material gave an assortment of substance and intuitive segments by the transformation model based upon the cognitive attributes distinguished models of students. A substance and intelligent part is an item which might prove to be usable, reasonable, and of commonsense incentive to the data handling measure for students to get to content and collaborate with others, for example, chapter by chapter guide, opening case, conversation discussion, and so forth (Gupta and Raghuwanshi, 2019).

\subsection{Cognitive Characteristics of Students}

This examination incorporated a neural organization of multi-layered forward-feed (MLFF) with the model for students to recognize students' manners of cognition relying on their perusing practices. The MLFF is a three layered composition: input, concealed, and yield layer (Fig. 2 ). It has been recommended by the researchers that it might be feasible to extricate mental data related with clients from their perusing practices, along with the usage of neural organizations is a potential way to perceive singular attributes (Mudassir, et al., 2016). A strong neural organization structure configuration ought to the structure 
of courseware based upon the web resources and will not need to change in accordance with the change in the structure of web pages (Purnomo,et al., 2017).

In this MLFF, the info layer is utilized to mirror clients' perusing practices addressed by students' reactions about different sorts of substance and intelligent segments and substance interface types. Four information factors were incorporated and each compares to one sort of info hub. The key info hub in the web architecture records the number of times the student clicks on the component. This info hub frequency has been derived in the equation 1 below. Further, in order to identify the overall selection ratio of the students clicking the same component has been calculated by dividing the number of clicks on the same component with total clicks on all the components. This has been depicted in the equation 2 below. Additionally, this study undertook the average amount time spent on one component by the student in the assigned web page has been recorded and it has been outlined into an equation 3 below. The initial components are placed in such a way on the web page so that they mirror the cognitive style of the students. The clicking of students on those components and the time spent on those components highlights the specific characteristic of the students learning via a web based system. Finally, there were few links highlighting the specific content that determined the specific characteristic of learning style. Therefore, the selection ratio of overall clicks on those specific links of the contents were also recorded and the calculation of the data has been derived in the equation 4 below. The number of times the student clicked on those specific content link on the web page was determined by " $m$ " as specified in the equation 4 . The 
components highlighted on the web page assist in identifying the cognitive learning style of the students (Wulandari,et al., 2019) and therefore, this has been reflected in the neural network framework for learning in the figure 2 below:

Selection frequency of component $i=$ Frequency of students dicls an component $i, i=1, n$

Selection ratio of component $i=$ Frequency of students' dickson componenti

Frequency of students' clicks on all components, $i=1, n$

Averoge staying time of component $i=$ Total Staying time of component $i /$ Frequency of students' dides on component $i, i=n$

Selection ratio of content link type $j=$ Frequency of students' clicks an content link type j)

Frequency of students' cticks on all content link rypes. $j=1, m$

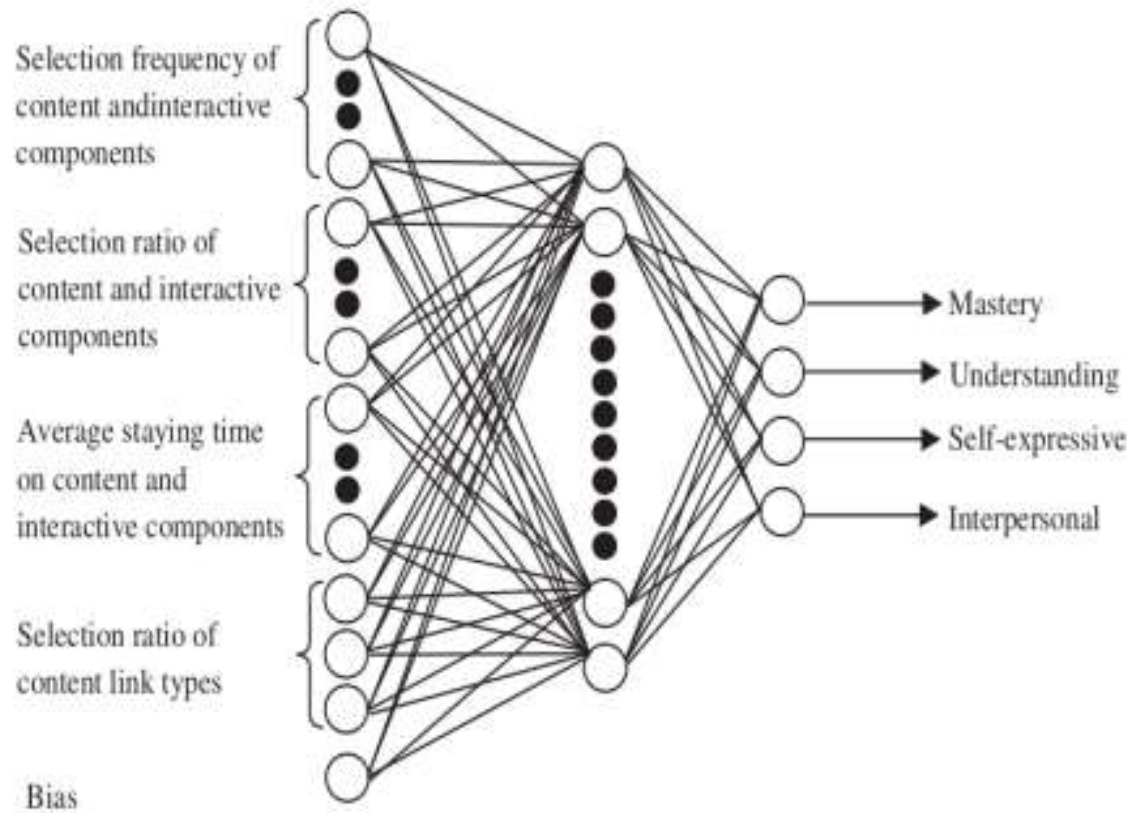
Input layer

Hidden layer Output layer

(Cognitive styles)

Figure 2: The neural network framework for learning 
The yield layer is utilized to address different sorts of highlights to be perceived in a MLFF and the quantity of yield hubs is straightforwardly determined by the issue. In this investigation, four particular manner of cognition, Interpersonal, Self-expressive, Comprehending and Mastery, should be distinguished. Consequentially, This MLFF is remembered by four yield hubs four yield. Each yield hub compares to one manner of cognition and a student's manner of cognition is resolved the yield hub related one having the most extreme worth acquired from the MLFF. The shrouded layer gives the handling force of a MLFFs, and the neural organization's capability of learning is influenced according to the quantity of concealed hubs (Valencia-Vallejo,et al., 2018). As proposed by Wulandari,et al., (2019), for order applications, the quantity of shrouded hubs is going to be the normal of info and yield hubs.

\subsection{Adaptation model: Web interfaces presented in accordance with the student's style of cognition}

Notwithstanding distinguish students' manner of cognition, another obstruction while consolidating students' mental characteristics into a multi-faceted system based upon web resources is the versatile introduction of resources to learn in conditions based upon web resources. This examination planned the multi-faceted interfaces of web resource for students with various manners of cognition by researching the connections in their cognitive manners and the manner in which a cooperation between them is built on the basis of system of learning through web resources (Marouf,et al., 2018).

In judging this, one exploratory system of learning through web resources having fifteen substance and 
intuitive parts (Table 1) was constructed (Purnomo,et al., 2017). Not at all like different parts being isolated from the content and are called as "catches", The learning resources are implanted with the two types of in-text hyperlinks namely, Graphic and Keyword. Figure 3 represents an interface of trial system of learning through web resource with the substance and intelligent segments at the top and the substance joins at the left of the window. For better portrayals of the system, English clarifications of the substance and intelligent segments on the screen captures are furnished in white marks with part depiction as recorded in Table 1.

Notwithstanding, the fifteen substance and intuitive segments, three substance interface types were characterized in the courseware structure: C, E, and X. The C-type interface was the standard of the learning way characterized by the courseware fashioners, among various instructional points. E-type joins (Explanatory) were joins guiding the learning way to the idea hubs for giving clarifications of an idea hub in the standard with C-type joins. Instead of giving clarifications, X-type joins (eXtensive) were utilized to give broad information on standard idea hubs with C-type joins (Gupta and Raghuwanshi, 2019). A total of 100 and 76 students who were enrolled in the diploma in computer science program were chosen to take an part in an examination exploring the connections between students' cognitive styles and perusing practices. Prior to the investigation, members were approached to finish a cognitive style assessment poll from Rukun and Irfan (2020) to recognize their cognitive styles. At that point they were approached to peruse the exploratory web-based learning system for $30 \mathrm{~min}$ in the 
PC lab. The subject of the learning content was "Ensuring People and Information: Threats and Safeguards". At the test time, the learning content had not been presented in the class and members had not perused the substance before the trial. Members' perusing practices were gathered in the $\log$ document by the system for investigation. In the wake of erasing fourteen members' unusual perusing information, which incorporated students' connects to outside web assets from the earliest starting point of the examination, perusing information from 100 and 62 members was investigated. Kindly allude to Table 1 for part portrayal.

Table 1: Expert System Components Identification

\begin{tabular}{|c|c|c|}
\hline $\mathrm{Na}$ & Costenent & Desciptisn \\
\hline 1 & frovest & 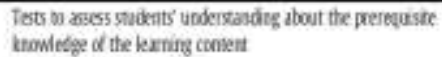 \\
\hline 2 & Talle af coneats & Listod the laning arters \\
\hline 3 & Introsuction & Onerview of the laning anters \\
\hline 4 & lextirg dijatives & Orflies $d$ meat whderx can leam fron the systen \\
\hline 5 & Opering ase & 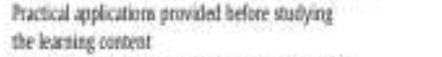 \\
\hline 6 & Ooung ale & 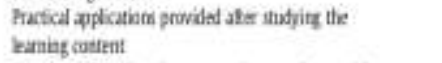 \\
\hline 7 & Clupter review & 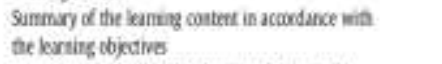 \\
\hline 8 & Glosary & 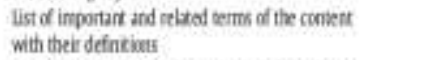 \\
\hline 9 & Retronce moserid & Etendev reading related to the karing conlent \\
\hline 10 & Appulx arreat ereats & 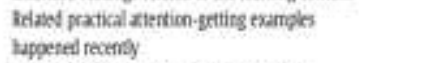 \\
\hline 11 & Sef evalutine & 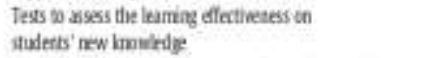 \\
\hline 12 & Desciswon foum & 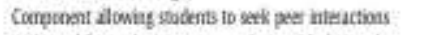 \\
\hline 13 & E-mul to rexher & A channel for stadeats wo arninicate wati the texher \\
\hline 14 & Keymont & 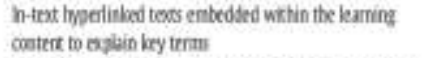 \\
\hline 15 & Graphik & 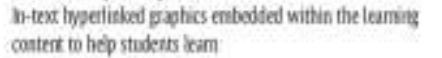 \\
\hline
\end{tabular}

This research focused on the two main outcomes in order to identify the cognitive style of learning in students that is based on the web architecture. First, it was the element which showed the overall selection ratio of the students clicking a specific component. Secondly, it was 
the average amount of time spent by the selected students in the experiment on specific component on the web page. These two elements have been re-specified in the below equations (5 and 6).

\section{Selection ratio of component $i=$ Frequency of students clicks on component $i$; \\ Frequency of sndents' clidis on all component $i=1, n$}

Avernge staying time of component $i=$ Totol Staying time of companent $i$ ifreguency of student' dids on campanent $i, i=1$, n $\quad$ (6)

The outcomes of the browsing behaviour of the students and their learning style has been depicted in the table 2 below. The number of students reflecting a specific cognitive style of learning has been identified in this table. This table 2 below shows that the majority of the students, i.e. around $51 \%$ of the students displayed the interpersonal learning style. Around $11 \%$ of the students showed the Mastery learning style. Almost $12 \%$ of the students showed an understanding style of learning. Finally, out of 162 students, 41 students (25\%) reflected the self-expressive style of learning vin the training phase. These learning styles of the students might be used to reflect upon the specific cognitive learning style of the students (Aggarwal and Woolley, 2019). These styles further are planned in the experimentation phase, where all the components determining the specific cognitive style will be used in order to reflect upon students' learning behaviour.

Table 2: Cognitive styles and browsing behaviors of Students

\begin{tabular}{lcc}
\hline Style & Number & Ratio \\
\hline Interpersonal & 83 & $51.23 \%$ \\
Mastery & 18 & $11.11 \%$ \\
Understanding & 20 & $12.35 \%$ \\
Self-expressive & 41 & $25.31 \%$ \\
Total & 162 & $100 \%$ \\
\hline
\end{tabular}

The outcomes show that choice proportions and normal remaining time had comparable patterns. These outcomes 
are derived with respect to the time spent by each student on specific component. Henceforth, it could be said that the higher ratio against each element of the cognitive style of learning shows that the average amount of time spent by each student on that specific component was more than the other. Alternatively, the lower ratio against each element of the cognitive style of learning shows that the average amount of time spent by each student on that specific component was less than the other. Beside this, the outcomes likewise uncover that there were huge various inclinations in choosing parts among students of various cognitive styles (Busari,et al., 2017) which could be, thusly, applied to plan versatile web interfaces for various cognitive styles. Table 3 sums up students' inclinations for content and intelligent parts. These findings were made the base in order to develop a web based framework for learning. All these elements of cognitive style and the content used for their identification can be used in the web based architecture for this study. The content displayed on each page and the time spent of each of the selected student for the experiment were recorded in the backhand, Which is consistent with the results of the study of both Mudassir Khan, M.A., 2016, Aggarwal, I. and Woolley, A.W., 2019.

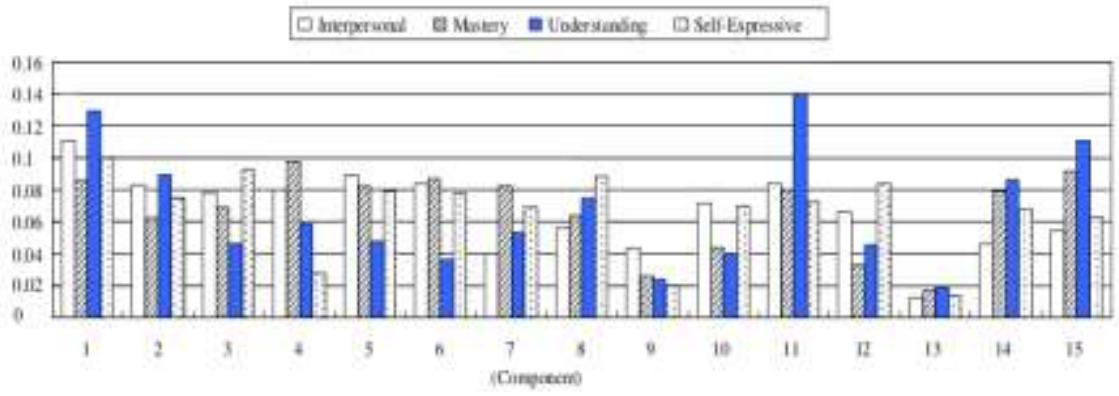

Figure 3: Student selection ratio graph 


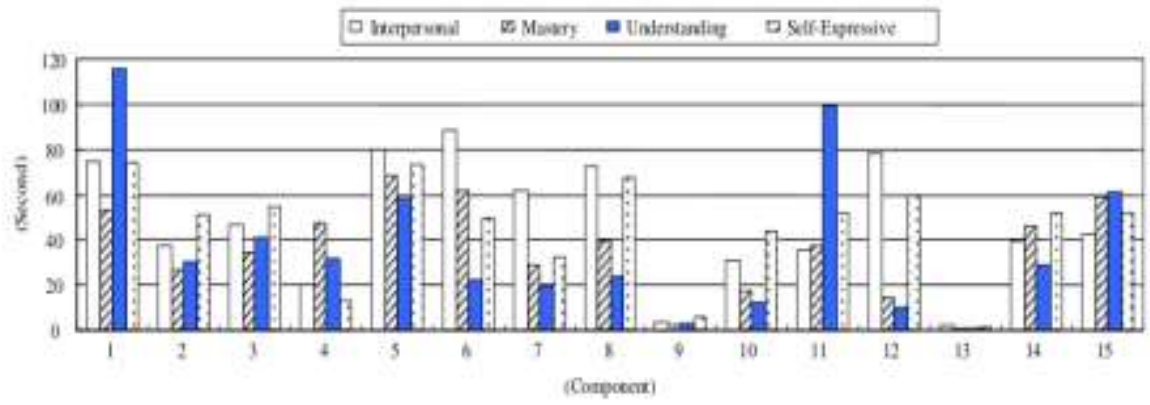

Figure 4: Normal Staying time on the web page

Table 3: Learning styles of the Components

\begin{tabular}{ll}
\hline Style & Preferred components \\
\hline Interpersonal & Pretest, Opening case, Closing case, Glossary, Discussion forum \\
Mastery & Learning objectives, Opening Case, Closing case, Chapter review, Graphic \\
Understanding & Pretest, Table of content, Opening case, Self evaluation, Keyword, Graphic \\
Self-expressive & Pretest, Introduction, Opening case, Glossary, Discussion forum \\
\hline
\end{tabular}

\section{Evaluations}

Following research questions were developed to answer in order to achieve the objectives of this study:

RQ1: What is the accuracy of the MLFF expert system in the identification of the cognitive style of the students?

RQ2: What effect does the proposed adaptive webbased system has on the engagement of students towards learning?

4.1. Evaluating the Cognitive Characteristics of Students

\subsubsection{Methodology Adopted for Training of Students}

The accumulated data for inquiring the connections between the manners of cognition of the students and scrutinizing rehearses indicated in the section 3.2 (Model 
of Adaptation: Presentation of web interfaces in accordance with students' manner of cognition) was utilized to set up the suggested MLFF, as the preliminary system of learning had fifteen substance, instinctive fragments and, other three kind of substance associate sorts, there were 49 data center points in the suggested MLFF (15 of them for section's frequencies, other 15 related with the portion's decision extent, 15 other for fragment's ordinary left over period of time, 3 others for assurance extents related to types of substance interface, and 1 related with the tendency center), also 4 yield center points (the four manners of cognition to be locate). MLFF training is essential for a monitored class for learning, demanding sets of information influenced data and needed yields (Valencia-Vallejo, et al., 2018). Research initiated upon the archive of the system log brought the data of examining rehearses of the students. Data that was yielded highlighted that the cognitive manners of the students were gotten after mentioning that the instrument related with the (Aggarwal, et al. 2019). 100 and 62 authentic records got used for getting ready. 114 of those records, were heedlessly picked because the data related with arrangement and the abundance of 48 of records filled in as the data on trial. Table 4 records scattering of data evaluated from various manners of cognition.

\subsubsection{Outcomes of Training}

Suggested MLFF and testing informational collections. The weight sets of the preparation added with the most noteworthy exactness proportions would be utilized for the accompanying examination. The precision proportion was characterized with the quantity of exact records of trials isolated through the absolute trails record quantity. The 
record of testing was supposed to be precise keeping in mind that the manner of cognition with the most extreme worth got from the MLFF was equivalent to the manner of cognition having the greatest worth acquired from the cognitive manner assessment poll. Exactness proportions determined each $5 \mathrm{~min}$ inside the perusing meeting (Table 5). Table 5 shows that the fleeting impacts ought to be thought of while distinguishing student cognitive styles during perusing. The most elevated exactness proportion didn't happen when utilizing the entire perusing meeting information $(30 \mathrm{~min})$. Inside the 25 minutes, normal precision proportions refined due to the utilization of longer perusing meeting information, consequentially, the exactness proportions diminished. Also, the most elevated precision proportions happened at various perusing spans among the styles. The most elevated exactness proportions for styles of Mastery and the Interpersonal happened while utilizing students' perusing information during 0-20 min and for Understanding and Self-expressive styles the most elevated precision proportions happened when utilizing perusing information of the students during 0-25 min.

Table 4: Cognitive Styles Evaluation Data

\begin{tabular}{|c|c|c|c|c|}
\hline shit & Nanter & Revo & Number of trining & Kumber of esting \\
\hline Ifterperond & 81 & $51213 x$ & 58 & 25 \\
\hline Mosery & is & $11.11 \mathrm{~s}$ & 13 & 5 \\
\hline thstersianding & 20 & 12358 & 14 & 6 \\
\hline Sell-appesive & 4) & 25316 & 29 & 12 \\
\hline Towal & 162 & 100 & 114 & 48 \\
\hline
\end{tabular}

Table 5: The ratios for accuracy

\begin{tabular}{|c|c|c|c|c|c|c|}
\hline \multirow[t]{2}{*}{ Sityle } & \multicolumn{6}{|c|}{ frowing dis } \\
\hline & 0.5 & $0-10$ & $2-15$ & $a-x$ & 025 & 0.38 \\
\hline Interpermanil & 65 & 725 & 706 & 45" & 34 & 5 \\
\hline Mastery & $40 \mathrm{n}$ & $60 \pi$ & $608 \pi$ & $\operatorname{sen}$ & $\operatorname{sen}$ & im \\
\hline Uodessuang & 338 & $50 \pi$ & $6 n$ & ax & $83 x^{2}$ & 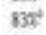 \\
\hline Sel espressir & 42 & $38 \pi$ & 678 & 335 & sea: & 752 \\
\hline Anelaye & $45 x$ & sca & 668 & sor & $35 x^{\circ}$ & 118 \\
\hline
\end{tabular}

The higlest accerag rote. 
Table 6: Web based Learning System Evaluation

\begin{tabular}{|c|c|c|c|}
\hline Grop & User cogsitive sype & Adaptime inserfares & Numbe \\
\hline 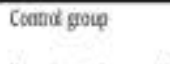 & 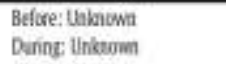 & No & 58 \\
\hline Experimenal grup A & $\begin{array}{l}\text { Beffore Known } \\
\text { Daning; Koowt }\end{array}$ & Yos & a \\
\hline Expreinertal gray $B$ & 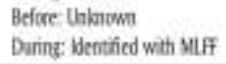 & Yos & 63 \\
\hline
\end{tabular}

\subsection{Evaluating the Suggested Web Based Approach for Learning}

\subsubsection{Experimental Settings}

The study samples included in this study were the students of Community College in Buraidah, Qassim University. These samples were selected from the fresh batch of students enrolled in the diploma in computer sciences program in the year 2020. These students were first asked to take part in the MLFF training and then their learning skills were tested based on the web-based learning system. The fresh students were selected for this study because they haven't ever been exposed to the web-based system learning before. These students were selected from the three different classes in order to test their cognitive style of learning. The evaluation of the selected students in the web based learning system is presented in the above table 6. This table shows that there were around 58 students in the control group, the experiment group A was done on the 49 students and the experimental group B included around 63 participants. In the control group, the students were not tested on the adaptive model on the web based expert system. In the experimentation sessions, web based system of learning was introduced. The results of the student's ratio are presented in the figure 3 . For the exploratory gathering A, students' cognitive styles were 
resolved prior to perusing by finishing the cognitive style assessment poll and the web interfaces adjusted to their styles were introduced from the earliest starting point. For the trial bunch B, students' cognitive styles were obscure prior to perusing and the traditional web interface (Fig. 3) was introduced at the outset. In the experimental group B session, web based architecture for the students' learning was introduced and the data related to the cognitive style of learning of the students was recorded. This experiment session involved the use of the web based system for at least 25 minutes by the selected students in the experimental group B session. The data related to the average time spent by each student on the web page was recorded in order to identify their learning styles.

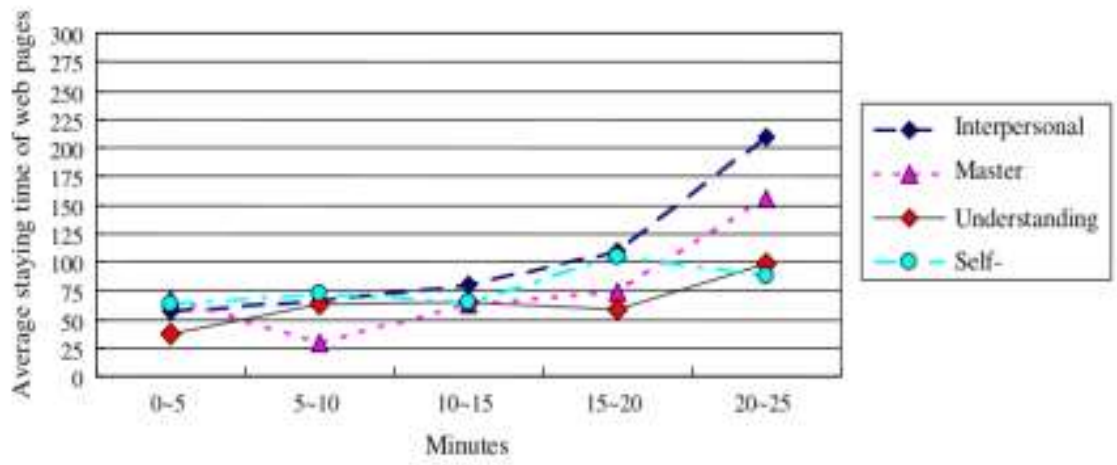

Figure 5: Control Group: Average Staying time

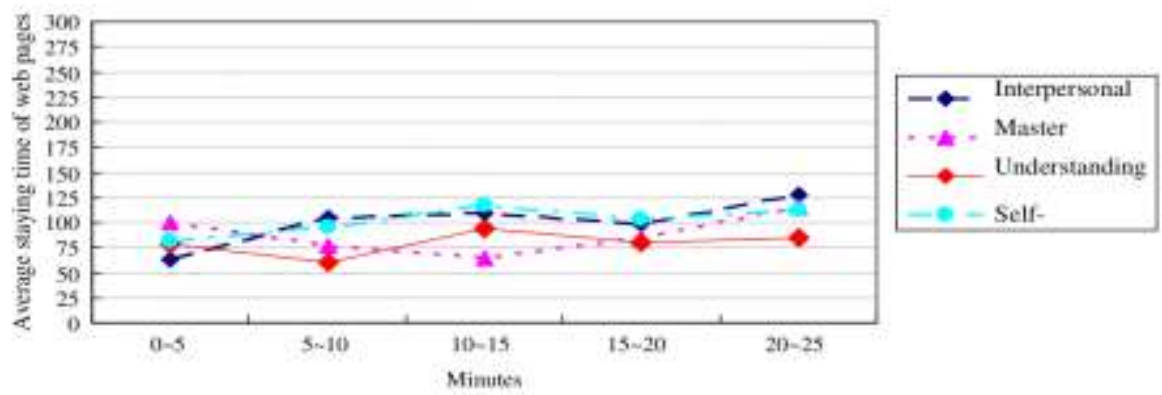

Figure 6: Experimental A: Average Staying time 


\subsubsection{Experimental Outcomes}

Average time spent on the web pages by any individual was for assessing the framework by addressing the commitment level of the students with material related with learning (Mefoh,et al., 2017). In this examination, each 5 min, the normal remaining season of web pages was determined as Equation (7).

Figure 6 and 7 highlights that the average remaining time for various cognitive manner of the students on web pages during the examination. In Figure. 6, for the control bunch utilizing traditional the way, from 0-20 minutes, the normal remaining web page time was inside a reach around of $25 \mathrm{~s}-100 \mathrm{~s}$ and with no huge contrasts with normal remaining time between the four manners. Notwithstanding, between the last 5 minutes (20-25 minutes), but the Self-expressive and Comprehending students actually possessed around the equivalent remaining period, Masterystudents and Interpersonal remained any further than previous 20 minutes. It was particularly valid keeping Interpersonal students in consideration, nearly leaving to explore web pages during the last 5 minutes, (normal remaining period was around $225 \mathrm{~s}$, near 5 minutes). It infers that Mastery and Interpersonal studentspaid focused consideration on the resources of learning for previous 20 minutes and became irritated a short time later which may be come about because of the interface not matching their manner of cognition. This is the constraint of traditional system based upon web resources and the issue being addressed in the 
examination, The span of looking for the information in order to prepare the MLFF to create different styles harmonized with the term of persuasion of web pages by the students. The purpose of making of the outcomes of MLFF might be impacted by the students: The most noteworthy precision proportions of recognizing the manner of cognition for Mastery styles and the Interpersonal happened while utilizing perusing information of the students between $0-20 \mathrm{~min}$, also, for Comprehending and Self-expressive styles the most noteworthy exactness proportions happened when utilizing students' perusing information during $0-25 \mathrm{~min}$.

Then again, Figure 7 that was for the exploratory gathering used the multi-faceted system of learning through web resources with the manner of cognition known before perusing highlights a point that the whole trial from 0-25 minutes, while the average residual period spent on the web pages stayed balanced within the scope of roughly 50 to 25 minutes, while having no big contrasts in the averages residual period between four of the styles. In spite of the fact that unlike the steady test bunch for A students that are Interpersonal, Figure 8 regarding the B exploratory gathering utilizing a multi-faceted system of learning through web resources having manners of cognition recognized while perusing the suggested MLFF, emphasizes that the entire trial of 0 to 25 minutes, similar with the test bunch $\mathrm{A}$, average residual period on webpages remained balanced while having no such big contrasts in the normal remaining period of time between the four manners, the results of this research are consistent with both studies Mefoh,et al., 2017, Koć-Januchta, et al., 2017. 


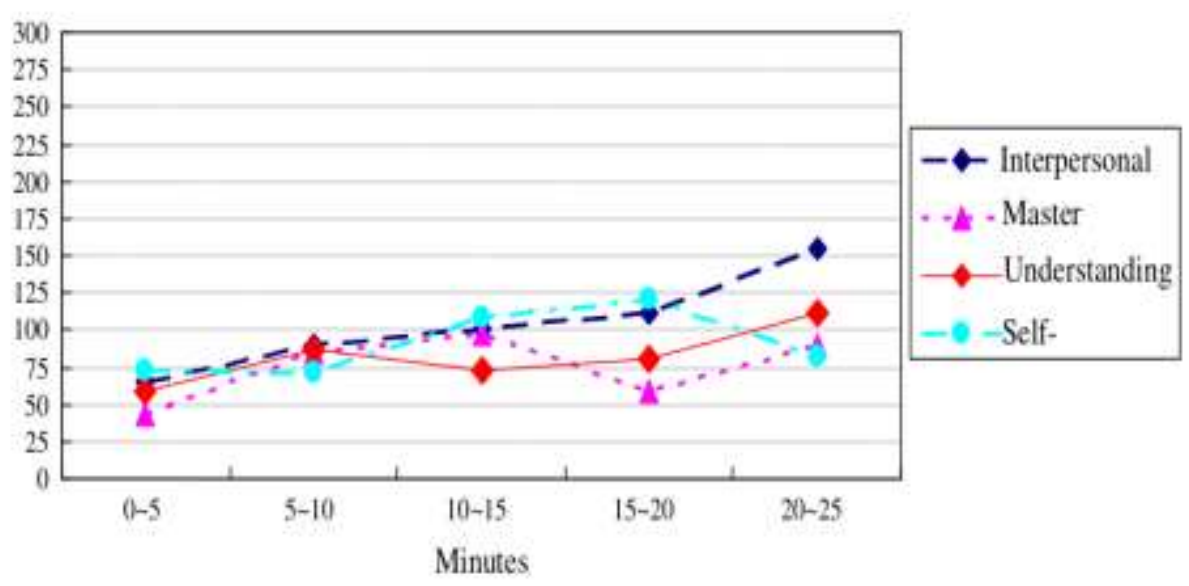

Figure 7: Experimental B: Average Staying time

\section{Condusions}

Despite the perceived fact of incorporating the cognitive manners of the students into configuration of the system based upon web seems to be advantageous while comprehending the manners of cognition are typically overlooked while planning versatile system of learning through web resources. This might because of the troubles of distinguishing student cognitive styles on the web and introducing versatile interfaces in conditions related with web. A big part of examination has collected data regarding the manners of cognition by assessing the students' poll completely. Be that as it may, this can cause students to feel awkward and isn't appropriate in functional settings. Along these lines, this examination built up a versatile system of learning through web resources zeroing in the manners of cognition of the students with an instrument that unpretentiously recognize students' manner of cognition, This was also confirmed by the results of the study of both Purnomo, S., Lestari, W. and Hastuti, I., 2017, Gupta, Y. and Raghuwanshi, G., 2019. 
The instrument of manner of cognition implicated in this examination was the Indicator of Myers-Briggs Type, based upon the hypothesis of cognitive attributes proposed by Jung. The rules proposed by (Nugrobo, et al., 2020) chosen it, it was based upon the model of two dimensional processing of data, substantial legitimacy along with an unwavering quality information, appropriate to be implemented with grown-ups. Grown-ups have mostly been dealt with, with this instrument, keeping in mind the adequate legitimacy along with the dependability information (Mulbar,et al., 2017). Two cognitive capabilities are its significant basis, judgment (in what manner an individual process or have a verdict about the consumed data) and insight (in what manner individuals find or assimilate data). It is based on two key cognitive capacities, insight (how individuals discover or assimilate data) and judgment (how individuals cycle or make judgment about the consumed data). Four cognitive manners (Interpersonal, Self-expressive, Comprehending and Mastery) are discussed from the two capacities.

The suggested system was made up of two sub models, the model of variation and the model of students. The model of students recognized the manner of cognition of students on the basis of the perusing practices they follow by using a balanced organization of multi-layered forwardfeed (MLFF) have no demands that the students should fill assessment surveys in order to make sure that they don't get irritated while learning. Transformation model at that point gave a multi-faceted web interfaces an assortment of substance and intelligent segments on the basis of attributes of cognition recognized in the model of client. The versatile interfaces in web were planned while examining 
connections of cognitive manners of the students and the perusing examples related with substance and intelligent segments (Margunayasa, et al., 2019).

Preparing of the MLFF and a test were led to look at the exactness extent of recognizing the manner of cognition of students while perusing a system of learning through web resources keeping the suggested MLFF in mind and the effect of the suggested versatile system of web on micromanagement while learning. The preparation aftereffects related with the suggested MLFF demonstrated an adequate normal most noteworthy precision proportion of $85 \%$ of the four major manners of cognition namely; Interpersonal, Self-expressive, Comprehending and Mastery. In addition, outcomes uncovered the worldly impacts ought to be thought of while recognizing students' cognitive styles during perusing. To start with, it isn't in every case better to incorporate however much information as could be expected to prepare the MLFF since the most noteworthy exactness proportion didn't happen when utilizing the entire perusing meeting information. Inside 25 minutes, the precision proportions got better as long lasting perusing meeting information was utilized and the exactness proportions at that point diminished. Second, the most noteworthy precision proportions happened at various perusing stretches among styles. The most elevated precision proportions for recognizing Mastery and the Interpersonal styles happened sooner before distinguishing Self-expressive and Comprehending styles (0 to 25 versus 0 to 20 minutes). A probable reason backing this that the students might start to become irritated subsequent to perusing the web webpage for a while. The trial and assessment of commitment of students were brought form 
the outcomes of the commitment of students to learn gave fleeting steady impact on learning. The probable benefits of MLFF for determining the manners of cognition of the students while perusing in application of learning from a system of web were observed by the outcomes. The outcomes confirms the capacity regarding the removal of mental data related with clients form their perusing conduct (Koć-Januchta, et al., 2017).

Two factors, the affirmation of cognitive manners of the students when perusing, also the presence of versatile interfaces of web, were utilized while allotting three classes of fresh students in into gatherings of three. Outcomes of the trial uncovered that the multi-faceted system of learning through web could essentially influence transient consequences for students' commitment in the learning process. For the utilization of traditional system by the students, however no huge contrasts were there about the normal remaining period for the different four manners from the earliest starting point, anyway Mastery and Interpersonal students remained any more in their last 5 minutes (20-25 minutes). This may be because of the "detecting" of the cognitive capacity "assumption".Mastery and Interpersonal styles both depend on detecting as a method discernment. Insight demonstrates what individuals discover or retain data thus mean for students' understanding on perusing web pages, which is the way toward getting mindful of data (Koć-Januchta, et al., 2017). From the results, it was found that the most of the students who showed the Mastery and Interpersonal learning style spent around 0 to 20 minutes on the web page. On the other hand, the students who showed self expressing and understanding learning style spent around 0 to 25 minutes 
on web page. These finding can be found in the table 5 above. This table presented the ratio of the overall time spent by each student and accuracy of identifying each component displayed on the web pages.

Then again, the students utilizing versatile system of learning through web resources either with the manner of cognition known prior to perusing or with manner of cognition distinguished while perusing the MLFF that was suggested, the normal remaining time period on web pages stayed balanced and with no critical contrasts during the normal remaining time among the four manner of learning from the earliest starting point to furthest limit of the analysis. This exhibited that the versatile system of learning through web resources by the manner of cognition of the students manner of cognition could viably upgrade the commitment of students in learning for Mastery and Interpersonal styles particularly This is a confirmation of the results of the study of both Aggarwal, I. and Woolley, A.W., 2019, Purnomo, S., Lestari, W. and Hastuti, I., 2017, Gupta, Y. and Raghuwanshi, G., 2019..

Taking the examination discoveries into account, it might be inferred about MLFF that it can possibly recognize students' brain science qualities, for example, cognitive styles without requesting that they complete any assessment surveys, and that the versatile system of learning through web resources fusing with cognitive manners of the students' can come up with the distinctive data association along with the interaction inclinations of students. Suggested versatile system of learning through web can bring much alluring interfaces rather than doing ordinary systems for upgrading the learning commitment of the students. This is conceivable not just for students 
with manners of cognition known prior to perusing yet additionally for students with manner of cognition distinguished during perusing. The outcomes give proof to the adequacy of the versatile web-based learning system with powerfully distinguishing students' cognitive styles during perusing, along these lines approving the exploration motivations behind this examination. Two restrictions of this examination ought to be thought of. The primary impediment respects the reception of MLFF for recognizing students' cognitive styles. In spite of the fact that MLFF could perform well in characterization, there are different methodologies, for example, rule-based systems and measurable systems. Stretched out examinations to analyze various methodologies could be considered later on. The subsequent constraint concerns the assessment of the versatile web-based system.

\subsection{Limitations of the Study}

In this research study, a web based framework was developed and tested in order to identify its effect on the learning styles of the students. This research projected the learning outcomes from the web based learning system which was developed keeping in mind the students' model and psychological characteristics of the students. However, this study ignored the varying learning approach of each student. Moreover, this study had excluded the teaching factor while conducting the experiment. The experiment was conducted on the students which belonged to three different classes and therefore, the teaching style of each teacher in these three classes must be different. This factor was also ruled out while conducting the experiment. Henceforth, the students learning in same class, by a same teacher, and with same ability to learn can be used in future research in order to identify the effects of this developed web based leaning style framework. 


\section{References}

- Aggarwal, I. and Woolley, A.W., 2019. Team creativity, cognition, and cognitive style diversity. Management Science, 65(4), pp.1586-1599.

- Aggarwal, I., Woolley, A.W., Chabris, C.F. and Malone, T.W., 2019. The impact of cognitive style diversity on implicit learning in teams. Frontiers in psychology, 10, p.112.

- Bhatti, S., Dewani, A., Maqbool, S. and Memon, M.A., 2019. A Web based Approach for Teaching and Learning Programming Concepts at Middle School Level. International Journal of Modern Education \& Computer Science, 11(4).

- Busari, A.H., Mughal, Y.H., Khan, S.N., Rasool, S. and Kiyani, A.A., 2017. Analytical cognitive style moderation on promotion and turnover intention. Journal of Management Development.

- Dominic, M., Francis, S. and Pilomenraj, A., 2014. E-learning in web 3.0. International Journal of Modern Education and Computer Science, 6(2), p.8.

- Engin, A. and Vetschera, R., 2017. Information representation in decision making: The impact of cognitive style and depletion effects. Decision Support Systems, 103, pp.94-103.

- Gupta, Y. and Raghuwanshi, G., 2019, February. Student Performance Evaluation Expert System Using Machine Learning to Make Cognitive Decisions. In Proceedings of International Conference on Sustainable Computing in Science, Technology and Management (SUSCOM), Amity University Rajasthan, Jaipur-India.

- Khamparia, A. and Pandey, B., 2018. SVM and PCA based learning feature classification approaches for E-learning system. International Journal of Web-Based Learning and Teaching Technologies (IJWLTT), 13(2), pp.32-45.

- Koć-Januchta, M., Höffler, T., Thoma, G.B., Prechtl, H. and Leutner, D., 2017. Visualizers versus verbalizers: Effects of cognitive style on learning with texts and pictures-An eyetracking study. Computers in Human Behavior, 68, pp.170-179.

- Margunayasa, I.G., Dantes, N., Marhaeni, A.A.I.N. and Suastra, I.W., 2019. The Effect of Guided Inquiry Learning and Cognitive 
Style on Science Learning Achievement. International Journal of Instruction, 12(1), pp.737-750.

- Marouf, A., Yousef, M.K.A., Mukhaimer, M.N. and Abu-Naser, S.S., 2018. An Intelligent Tutoring System for Learning Introduction to Computer Science.

- Mefoh, P.C., Nwoke, M.B., Chukwuorji, J.C. and Chijioke, A.O., 2017. Effect of cognitive style and gender on adolescents' problem solving ability. Thinking Skills and Creativity, 25, pp.4752.

- Mudassir Khan, M.A., 2016. The scope of E-learning in the computer science \& technologies. International Journal of Computer Science Engineering and Information Technology Research (IJCSEITR), 6(6), pp.93-98.

- Mulbar, U., Rahman, A. and Ahmar, A., 2017. Analysis of the ability in mathematical problem-solving based on SOLO taxonomy and cognitive style. World Transactions on Engineering and Technology Education, 15(1).

- Nugroho, A.A., Nizaruddin, N., Dwijayanti, I. and Tristianti, A., 2020. Exploring students' creative thinking in the use of representations in solving mathematical problems based on cognitive style. JRAMathEdu (Journal of Research and Advances in Mathematics Education), 5(2), pp.202-217.

- Prickett, T., Walters, J., Yang, L., Harvey, M. and Crick, T., 2020, June. Resilience and Effective Learning in First-Year Undergraduate Computer Science. In Proceedings of the 2020 ACM Conference on Innovation and Technology in Computer Science Education (pp. 19-25).

- Purnomo, S., Lestari, W. and Hastuti, I., 2017. Expert System Design for Guidance of Information Technology (It) Technopreneurships Based on Students Personal Characteristics. International Journal of Engineering Research and Technology (IJERT), pp.2278-0181.

- Rukun, K. and Irfan, D., 2020, September. Identification of Student Learning Style in Determining Learning Media Using Expert Systems. In Progress in Social Science, Humanities and Education Research Symposium (pp. 22-26). Redwhite Press.

- Saini, K., Wahid, A. and Purohit, G.N., 2014. Traditional learning versus web based learning: performance analysis. International 
Journal of Computer Science and Information Technologies, 5(4), pp.5182-5184.

- Valencia-Vallejo, N., López-Vargas, O. and Sanabria-Rodríguez, L., 2018. Effect of Motivational Scaffolding on E-Learning Environments: Self-Efficacy, Learning Achievement, and Cognitive Style. Journal of educators online, 15(1), p.n1.

- Wasim, J., Sharma, S.K., Khan, I.A. and Siddiqui, J., 2014. Web based learning. International Journal of Computer Science and Information Technologies, 5(1), pp.446-449.

- Wulandari, N., Abdullah, A.G. And Kustiawan, I., 2019. Development Of An Application Of Critical Thinking Skills Tools Using Fuzzy Expert System. Journal of Engineering Science and Technology, 14(6), pp.3073-3086.

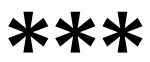

